\title{
PIRES, Alex Sander; ROSÁRIO, Pedro Trovão do; BAHAMONDE, Ruben. (Org.) Compliance: perspectivas e novas dinâmicas. Coimbra: Almedina, 2019. 101 p. ISBN 978-972-40-8268-4.
}

\author{
POR RODRIGO LUÍS ZIEMBOWICZ*
}

rlzdireito@hotmail.com

GALILEU - REVISTA DE DIREITO E ECONOMIA * e-ISSN 2184-1845

Volume XX $\cdot 1^{\text {st }}$ July Julho $-31^{\mathrm{TH}}$ December Dezembro $2019 \cdot$ pp. 199-202

DOI: http://doi.org/10.26619/2184-1845.XX.2.1.01

Esta obra resulta de uma soma de esforços do Centro de Investigação Ratio Legis, do Departamento de Direito da Universidade Autónoma de Lisboa, do Instituto Universitário do Rio de Janeiro e do Ethical \& Compliance International Institute, consolidando o conteúdo e os debates promovidos em dois congressos jurídicos, realizados em Lisboa (Portugal) e no Rio de Janeiro (Brasil), tendo por temática o sistema de compliance, com ênfase na sua interconexão com a cultura de paz e com a dignidade humana. O assunto é relevante e atual, representando um tema discutido de forma constante e crescente na seara acadê- mica, bem como nas instituições estatais e privadas.

Efetivamente, passada mais de uma década do início da recessão econômica de escala global, 'e é chegado o momento de reencontrar o equilíbrio no ordenamento jurídico, na definição das políticas estatais (especialmente criminais, administrativas e econômicas), bem como nas relações privadas, com base nos mais elevados valores e padrões éticos, lastreados na dignidade da pessoa humana e nos efeitos que devem irradiar desta convicção. Nesse aspecto, a presente obra, elaborada por juristas, acadêmicos e

\footnotetext{
1 A partir dos abalos econômicos que surgiram na década passada, principalmente a partir do colapso financeiro (de alcance global) de 2008, que ainda produz efeitos negativos nas economias de muitos países, causando prejuízos evidentes à qualidade de vida das pessoas (principalmente das menos afortunadas), a sociedade vem rediscutindo $\mathrm{e}$ buscando aperfeiçoar (especialmente) os seus sistemas financeiros (privados e públicos) e as políticas econômicas. Revelou-se, numa clara e nova dinâmica social, que não são mais tolerados os constantes prejuízos econômicos e sociais impingidos ou diluídos entre todos os indivíduos (direta ou indiretamente), quando os lucros de manobras financeiras e empresariais nocivas e imorais (embora nem sempre ilegais) são concentrados entre pouquíssimos indivíduos. Efetivamente, houve (inclusive) uma nítida expansão do Direito Penal e de outros ramos jurídicos, com o fito de prevenir, detectar e também sancionar as condutas que lesionem (ou coloquem em grave risco) bens jurídicos relevantes, de cariz coletiva. Visa-se, de fato, a estabelecer um certo controle mínimo e acompanhamento sobre pessoas físicas e coletivas, atividades políticas, econômicas e mercados, que possuíam pouca ou nenhuma regulação, deficiência esta que viabilizou, em grande medida, o desequilíbrio financeiro que resultou na grande recessão econômica que, infelizmente, ainda produz efeitos danosos.
} 
profissionais do Direito de Portugal, do Brasil e da Espanha, oferece uma perspectiva diferenciada quanto ao compliance, compreendido como paradigma e programa de integridade, que tem evoluído e proporcionado tanto a criação quanto a constante ampliação das medidas, a serem adotadas por agentes públicos e privados, no sentido de prevenir e evitar o desatendimento a normas e a princípios éticos estabelecidos nos respectivos ordenamentos jurídicos e em códigos de conduta. Com efeito, esta adoção de boas práticas tem envolvido tanto os órgãos públicos quanto a sociedade civil na busca por relações humanas e institucionais íntegras, com maior responsabilidade e, obviamente, um fortalecimento ético das ações (e omissões) individuais e coletivas.

Nesse rumo, os sete textos que compõem este livro analisam o compliance sob a perspectiva da cultura de paz e da dignidade da pessoa humana, ${ }^{2}$ sob diversos matizes.

A primeira abordagem, intitulada " $O$ compliance como instrumento para o fortalecimento da cultura de paz", manuscrita pelo também organizador Alex Sander Pires, apresenta um escorço histórico e examina as iniciativas e os instrumentos utilizados pelas Nações Unidas para estabelecer um sistema de paz a nível mundial, entendido como uma "reunião de povos" com fins humanitários, com o firme propósito de manter a paz, promover a segurança internacional e viabilizar o exercício dos direitos fundamentais. Após, apresenta reflexões sobre a aproximação do compliance ao sistema de cultura de paz, tanto no aspecto normativo quanto ideológico, analisando o envolvimento de diferentes setores da sociedade nessa busca do resgate moral dos indivíduos, no fortalecimento da ética e de uma consciência coletiva através da educação.

O texto seguinte, "A era do compliance no século XXI", de Cláudio Carneiro, investiga os escândalos de corrupção de maior repercussão internacional, envolvendo agentes públicos e empresas transnacionais, bem como o desenvolvimento de instrumentos de gestão e de políticas de boa governança por organismos internacionais, os quais objetivam a promoção de uma cultura sustentável de integridade. Posteriormente, apresenta diversos aspectos dos programas de compliance, desde princípios e regras de conduta ética até medidas para ampliar e aperfeiçoar a transparência e a difusão de informações ao público, facilitados pela tecnologia digital moderna. Prosseguindo, traz a lume diversos pontos de reflexão, inclusive quanto à necessidade de gerenciamento de riscos, de modo a evitar condutas ilícitas ou não condizentes com os

$2 \mathrm{Na}$ apresentação, o organizador e autor Pedro Trovão do Rosário anota que o sistema da cultura de paz das Nações Unidas foi concebido para, entre outras diretrizes, difundir uma educação voltada para o aperfeiçoamento ético e normativo das relações entre os seres humanos, bem como uma resolução pacífica dos conflitos e a adoção de instrumentos que aumentem a transparência e a responsabilidade dos atores governamentais e privados, envolvendo todos os indivíduos, conceitos esses que possuem forte interligação com o compliance. 
valores, visão e objetivos de empresas e de órgãos públicos.

Por seu turno, "O compliance trabalhista como mecanismo de promoção do trabalho decente e de aperfeiçoamento da dinâmica corporativa", de Fábio Goulart Villela, examina a evolução da sociedade (ocidental), a qual culminou no reconhecimento da dignidade da pessoa humana como o valor central da ordem jurídica internacional, irradiando os seus efeitos sobre as mais diversas constituições de Estados Democráticos de Direito. Pondera o autor que o direito a um trabalho decente é um dos mais importantes fatores para promover a concreção da dignidade humana, passando a analisar e propor o debate sobre as suas nuances em relação ao compliance trabalhista. Trouxe à tona, ainda, a discussão sobre os pilares de sustentação de um sistema de integridade que, além de uma cultura de conformidade e ética, deve viabilizar um trabalho digno para o trabalhador e a otimização da dinâmica das empresas.

A análise sobre "O compliance e os Estados europeus", de Pedro Trovão do Rosário, um dos organizadores da obra, investiga o atendimento das normas da União Europeia pelos Estados-membros, inclusive quanto à efetiva transposição e aplicação da legislação estabelecida nos prazos fixados, além de abordar os procedimentos em caso de infração e os efeitos decorrentes dessa conduta. Debruça-se o autor, ainda, sobre outras questões de enorme relevância, como a recomendável adoção pelos Estados-membros de um sistema de compliance (da mesma forma que milhares de empresas europeias) para corrigir suas deficiências, acompanhar regularmente suas obrigações e prevenir violações e outras condutas irregulares no seio da UE. Ademais, traz ao debate alguns exemplos de normas rigorosas, que preveem elevadas sanções de caráter administrativo ou penal em caso de descumprimento de normas de compliance por pessoas jurídicas (ou equiparadas), ao tempo em que os Estados-membros descumprem reiteradamente a legislação da UE sem que lhes seja exigida adoção de um programa de integridade, impondo-se a discussão sobre o tema no seio da sociedade europeia.

$\mathrm{O}$ autor Ruben Bahamonde, que também participou da organização do livro, apresentou o texto "Antitrust compliance", no qual investiga a integridade do comportamento de empresas e dos seus representantes em relação ao direito concorrencial. Pondera, principalmente, fatores relativos aos custos e benefícios da implantação de um sistema de integridade, em busca da difusão e do atendimento de regras de conduta dirigidas não somente aos diretores e operadores jurídicos das empresas, mas também aos demais setores, como administradores intermédios, sócios e trabalhadores. Traz a lume, ainda, pontos relacionados aos prejuízos econômicos causados às empresas pelo descumprimento de normas (ambientais, fiscais, trabalhistas e outras), diante dos danos à reputação do empreendimento no mercado e da aplicação de sanções. Após, trata do regime de concorrência europeu e brasileiro, investigando os ilícitos concorrenciais, apresentando 
diversos casos para estudo e seus respectivos dados, acrescentando ao debate as principais características e modelos de compliance.

O artigo "El compliance corporativo y la seguridade jurídica, hacia un nuevo derecho", de Maria Teresa Posada Fernández, analisa as normas do ordenamento jurídico espanhol relativas aos programas de cumplimiento normativo, especialmente quanto às possibilidades de atenuar ou de eximir as pessoas jurídicas (e também físicas) de uma responsabilização criminal. Perscruta, também, o compliance entendido como uma cultura corporativa, objetivando evitar ou diminuir riscos, gerar segurança jurídica e otimizar o empreendimento. Prosseguindo, adiciona à discussão uma avaliação histórica europeia sobre o tema e a importância de sistemas efetivos de cumprimento de normas e de prevenção a delitos, abordando os respectivos benefícios e os danos que podem decorrer da sua falta, principalmente quanto à responsabilização penal de uma empresa ou dos seus componentes.

O estudo intitulado "O compliance trabalhista como instrumento de transformação cultural para a dignidade humana", de Valéria Ribeiro Bruno, examina a evolução da cultura de integridade, voltada para o cumprimento do ordenamento jurídico e para o atendimento a princípios éticos nas organizações. Indica, também, o seu potencial como instrumento para otimizar e fortalecer tanto as empresas quanto os órgãos públicos, ao desenvolver honestidade, comprometimento, competência e transparência no seio das instituições. Como meio de aprimoramento organizacional nas relações trabalhistas, analisa as técnicas de compliance e os benefícios que pode ofertar a todos os envolvidos, quer seja no processo de contratação, quer seja durante o exercício laboral e, inclusive, após o término do contrato de trabalho. Traz à discussão, também, a conexão entre esta promoção de um sistema integridade legal e ética e a dignidade humana.

Desse modo, conclui-se que esta obra, além de examinar múltiplas facetas e características do sistema ou cultura de compliance, tem elevado mérito por trazer à baila uma série de pontos de reflexão sobre o tema, voltando-se principalmente ao aperfeiçoamento de instituições privadas e públicas, cooperando, assim, para o aperfeiçoamento da comunidade humana. Os textos ofertam, ainda, diversos aspectos relativos à necessidade de modificar a cultura jurídica ocidental, no sentido de valorizar e utilizar métodos preventivos e consultivos, em detrimento de uma tendência de resolução de problemas através do contencioso judicial, que resulta num elevado custo para as empresas, para o Estado e para o tecido social como um todo.

* Doutorando em Ciências Jurídicas da Universidade Autónoma de Lisboa

\section{Como citar esta Recensão Bibliográfica:}

ZIEMBOWICZ, Rodrigo (2020). Recensão Crítica de: PIRES, Alex Sander; ROSÁRIO, Pedro Trovão do; BAHAMONDE, Ruben. (Org.). Compliance: perspectivas e novas dinâmicas. Coimbra: Almedina, 2019. 101 p. ISBN 978-972-40-8268-4. 